\title{
The Food App is Watching You: The Relationship between Daily Algorithmic Control and Meaningful Work and the Role of Job Crafting
}

\author{
Lorenz Verelst \\ KU Leuven \\ lorenz.verelst@kuleuven.be
}

\author{
Rein De Cooman \\ KU Leuven \\ $\underline{\text { rein.decooman@kuleuven.be }}$
}

\author{
Marijke Verbruggen \\ KU Leuven \\ marijke.verbruggen@kuleuven.be
}

\begin{abstract}
App work disrupted our traditional understanding of work as it introduced new technologies, such as algorithmic control. Based on the job characteristics theory, we put forward an important drawback of algorithmic control and a practice that might mitigate it. We test whether algorithmic control obstructs experiences of meaningful work through a lack of motivating job characteristics and the buffering role of bottom-up work design (i.e. job crafting). We conduct a daily diary study among 51 Belgian food app workers and test within-person relationships. Results show that on days that app workers experience high algorithmic control, they perceive their work as less meaningful than on days with little algorithmic control. Although daily motivating job characteristics could not explain this negative relationship, we found job crafting to enable app workers in attaining motivating job characteristics and meaningful work. Thereby we emphasize the importance of both top-down and bottom-up work design in a strive for meaningful work.
\end{abstract}

\section{Introduction}

The world of work around us has been - and still is - changing. Small startups developing revolutionary technology rapidly changed into multinationals and even created a new work system, known as gig work. As one variant of gig work, app work refers to platform organizations, such as Deliveroo and Uber, that use algorithmic technology to match temporary on-demand jobs (i.e., 'gigs') with independent workers [1]. In specific, app work is a form of labor whereby apps manage all working activities by setting minimum quality standards of service, and selecting and directing the individuals who perform the work [1]. Although app work is ubiquitous in our daily lives and, therefore, might seem similar to our 'petrified images of work', it is in fact very different [2]. While a 'flesh-and-blood' supervisor is common sense in traditional work contexts, algorithms are used to control workers in the context of app work [3]. Such algorithmic control closely monitors and influences app workers' daily actions so that it aligns with the market logic goals of the app provider [4].

Recently, researchers have started to explore the consequences of algorithmic control on app workers' work experiences. For example, studies have reported that algorithmic control might lead to certain psychological costs as it positively correlates with exhaustion and signals of distrust [5, 6]. Despite this growing interest in algorithmic control, two crucial questions remain unanswered. The first question is: how does algorithmic control affect app workers' perceived work meaningfulness (i.e., the degree to which one accomplishes valuable, significant, or worthwhile goals) [7]? Due to algorithmic control, app workers no longer have agency to decide how to do their job [8]. This, however, is at odds with the assumption that workers need agency as a fundament to pursue their own goals and ambitions and, therefore, to create meaningful work [9]. Although it was primarily assumed that appworkers only seek to work for financial gains, recent literature on the sociology of work unraveled that many app workers indeed pursue meaningfulness in their job $[10,11]$. Unfortunately, the effects of algorithmic control on perceived work meaningfulness have mostly been overlooked. The second question is: how can app workers cope with algorithmic control? Because algorithmic control is related to certain psychological costs, many individuals aim to seek strategies to avoid these costs [12]. Although some of these strategies have been investigated in the general context of gig work [e.g. $12,13]$, we need insights into these techniques in the specific context of app work.

In the present study, we aim to answer these two questions by investigating whether and why algorithmic control is linked to work meaningfulness and how job crafting (i.e., a way to actively change one's job characteristics) as a bottom-up work design strategy might play a role. This is important since meaningful work is a fundamental psychological need for selfexpression and is known as a key antecedent of several organizational outcomes (e.g., intrinsic motivation and work performance) [7]. To do so, we conduct a daily diary study in which we adopt an actor-centric approach. We focus on proximal - i.e., daily - work experiences 
as previous research has shown that algorithmic control is episodic in nature, and thus fluctuates from day to day: on days that the demand for gigs and the supply of workers is balanced, less monitoring and occurs. In contrast, on days with an imbalance, more monitoring and influencing is needed to reduce this imbalance and to meet the app provider's goals $[2,14]$.

This study provides at least two contributions to the still infant literature on app work. First, we answer the call of several scholars [e.g., 4, 16, 17] to put forward theory on work design as a fruitful avenue to understand the impact of new technologies on work. In particular, we integrate algorithmic control with each of the three job characteristics that predict meaningful work according to job characteristics theory (hereafter JCT) [18]: skill variety (i.e., the extent to which an individual needs a diverse range of competencies and talents to do the job), task identity (i.e., the extent to which an individual can perform tasks within the job from start to finish with visible results), and task significance (i.e., the impact that the job has on other peoples' lives or work). Second, we answer the call of Parker and Grote to investigate "how people might craft the impact of new technologies" [17, p. 31] by proposing job crafting as a hands-on strategy that food app workers can apply to cope with the negative consequences of algorithmic control. Because app providers generally do not take many top-down initiatives to improve the quality of app work, this bottom-up approach of work (re)design might be particularly interesting for app workers [19].

We start by reviewing the literature on the focal variables in this study. Afterward, we explain how these variables might be related to each other. Next, we present our methods and results and eventually end with discussing our findings and contributions.

\section{Literature review}

\subsection{Food app work}

Duggan et al. [1] conceptualized app work as a key variant of gig work, next to capital platform work (i.e., online platforms such as Airbnb that enable people to sell or rent out raw materials or other assets) and crowd work (i.e., platforms such as Amazon Mechanical Turk that enable organizations to outsource work assignments to freelancers). All three variants indeed share the main characteristics of gig work: It is about short-term and temporary tasks executed 'on demand' by independent workers through the intermediary of a digital platform [20]. App work, however, differs from the other variants as it is about performing tasks (rather than sharing capital as with capital platform work) in an offline setting (rather than online as with crowd work). Within app work, we further make a distinction between non- transport (e.g., dog walking) and transport services [21]. This latter category is distinguished into two subcategories: non-food transport (e.g., Uber) and food transport (e.g., Deliveroo). As outlined above, this study particularly focuses on the latter category.

Within food app work, a quadrilateral relationship between different actors occurs (see also Figure 1). First, a requester (i.e., a consumer) uses the app of a food platform provider to order a meal from a supplier (i.e., an affiliated restaurant). The app notifies this to the restaurant, which prepares the order. At the same time, the app notifies the preferred worker (i.e., the app worker) to execute the delivery from the supplier to the requester. To choose the preferred worker, algorithms that make a decision based on multiple parameters (e.g., distance to the restaurant) are used [22]. This daily decision-making process, however, is still a 'blackbox', as the food app providers are not transparent about the underlying logic of the algorithms' decisions [4].

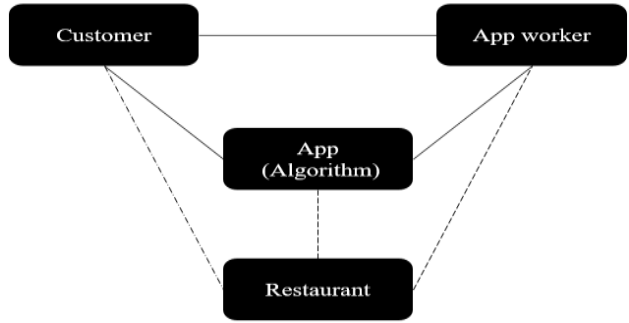

Figure 1. The quadrilateral relationship between the different actors in food app work

\subsection{Algorithmic control}

Although decision-making is an important function of the algorithms behind the food apps, an emerging literature stream has identified a bunch of other algorithmic management functions, such as algorithmic control [3, 16]. Algorithmic control is a form of organizational control embedded in the broader organizational structure and strategy, and is defined as an influence process that seeks to align workers' daily actions with the organization's objectives [23]. Duggan and colleagues [1] conceived a two-dimensional conceptualization of algorithmic control. On the one hand, 'soft' control mechanisms aim to indirectly change workers' behavior through motivation, loyalty, integrity, inspiration, standards, or values [24]. For instance, Deliveroo gives riders who provide the most reliable services priority access to the system in which they can book their work shifts [22]. On the other hand, 'hard' control refers to more severe and formalized control that directly aims to create high-performance expectations and the need to satisfy organizational and customer needs [1]. For instance, Uber Eats 'punishes' 
food app workers who repeatedly refuse rides with a temporary deactivation on the app [14].

In order to make algorithmic control possible, food app providers monitor food app workers' daily actions [16]. In particular, the self-learning algorithms behind the food apps collect, store, analyze, or report a broad spectrum of heterogeneous data such as customer satisfaction rates, acceptance/cancelation rates, changing GPS locations, and data concerning the time usage (e.g., travel time to the restaurant) [4]. This data is used to define and enforce rules and standards to ensure that workers' activities are vis-à-vis the metaorganizational goals of the app provider [4, 25].

\subsection{Meaningful work}

Experiencing meaningful work is recognized as a key psychological state at work [26]. As such, a rich body of literature on meaningful work has been developed. When approaching meaningful work through the lens of time, it contains both a stable subjective mindset of a worker (e.g., one's work orientation) and a dynamic experience that can fluctuate for a single worker over psychological states and working conditions [27]. For instance, zookeepers might see their work as a calling more than accountants, but a zookeeper might be more successful in fulfilling this calling on certain days (e.g., with a lot of animal care tasks) than on other days (e.g., with many administrative tasks) [28]. This dynamic within-person approach can be further conceptualized in multiple ways, depending on the theoretical background [29]. For instance, some scholars have explored meaningful work within the workplace spirituality literature and proposed that workers have an inner life that is nourished by meaningful work [30]. Most scholars, however, have conceptualized meaningful work as a psychological state deriving from certain job characteristics [29].

JCT [18] was among the first theories proposing such job characteristics and has received much confirmation of its explanatory power in reviews and meta-analyses [e.g., 31]. As outlined earlier, the theory identifies three core job characteristics as vital sources to perceive meaningful work: skill variety, task identity, and task significance [18]. It should be noted that the theory also proposes autonomy and feedback (from the job) as two other important job characteristics. Although these two job characteristics are not an antecedent of meaningful work, they lead to other critical psychological states: responsibility and knowledge of results. In turn, all psychological states - among others meaningful work - result in various beneficial outcomes (e.g., intrinsic motivation, job satisfaction, quality work performance, and low absenteeism) [18].

\subsection{Job crafting}

Since Wrzesniewski and Dutton [32] introduced the term job crafting in 2001, it has received considerable attention in the literature. In contrast to the notion that jobs can only be designed by managers (i.e., top-down), job crafting recognizes that workers themselves can play an active role in (re)designing - or 'crafting' - their job. Central to job crafting is that it is about active changes with a pro-self-focused purpose and without the need of a supervisor's approval [33]. Wrzesniewski and Dutton [32] have identified three forms of job crafting that each aim to improve one's work experiences and, as such, one's meaning of work: task crafting, relational crafting, and cognitive crafting. First, task crafting is about reconstructing the number, scope, or type of job tasks (e.g., by adding or withdrawing a task). Second, relational crafting involves changing the quantity or quality of interactions with others (e.g., by interacting more often with colleagues). Finally, cognitive crafting refers to altering how one views or frames the job (e.g., by changing the perceived importance of the job). While the first two types are behavioral in nature, the latter type is a cognitive form of job crafting [33].

Throughout the years, several scholars tried to advance the concept of job crafting [34, 35]. For instance, Bunning and Campion [35] additionally made a distinction between approach and avoidance job crafting. While approach job crafting is directed towards problem-focused and improvement-based goals (e.g., adding a joyful task), avoidance job crafting is directed towards reduction-focused goals (e.g., withdrawing a demanding task). Scholars reported that approachoriented forms of job crafting are indeed beneficial in optimizing one's work experiences, while avoidanceoriented forms of job crafting actually worsen one's work experiences as they reduce work engagement and create distance between the worker and the job [36].

In line with the other focal variables in this study, job crafting is found to fluctuate on a daily basis. Indeed, although individuals have a relatively stable tendency to craft their job, the degree of job crafting is triggered by specific events on a particular day.

\section{Hypotheses Development}

\subsection{The relationship between daily algorithmic control and daily meaningful work}

We expect that when algorithmic control is clearly present on a particular day, it will negatively impact the experience of meaningful work through its relationship with three important motivating job characteristics as proposed by JCT (i.e., skill variety, task identity, and task significance). First, algorithmic control will 
decrease skill variety in that it leaves no room to decide how to execute work and it solves many problems that workers were previously faced with [16]. As such, workers will have fewer opportunities to exercise and develop skills, resulting in less skill variety [37]. Second, task identity will decrease in that workers tend to 'work for data' rather than providing a service [25]. In that sense, workers might be motivated to strive for good ratings, rather than for providing a good service. Put differently, tasks might become 'datasatisfying' rather than customer- or operations-focused [25]. As such, workers might get detached from their work process and work outcomes. Finally, algorithmic control might reduce task significance. Because workers are continuously being controlled, they will perceive themselves as a cog within a machine instead of a service provider for customers [22]. Consequently, it might be harder to see the importance of their job for themselves and their customers. To summarize, based on JCT we expect a direct and a mediation effect:

Hypothesis 1a: Daily algorithmic control is negatively related to daily meaningful work

Hypothesis 1b: The relationship between daily algorithmic control and daily meaningful work is mediated by daily skill variety, task identity, and task significance

\subsection{The buffering role of job crafting}

Although we propose a negative relationship between algorithmic control and meaningful work, we do not expect this relationship to be equally strong for every food app worker. In fact, since many workers strive for meaningful work, they might try to compensate for the lack of meaningful work experiences [33]. Based on JCT, we propose that food app workers can do so through job crafting, and more specifically through approach-oriented forms of job crafting. Indeed, while approach-oriented job crafting buffers negative experiences, avoidance-oriented job crafting might boost them since app workers will decrease their efforts and work role identities [36].

Debus et al. [38] found that (approach-oriented) job crafting indeed buffers negative outcomes. In particular, they found that overqualified employees were significantly more inclined to withdraw from their work, but not when they engage in high (compared to low) levels of job crafting. In this vein, algorithmic control might be negatively related to skill variety, task identity, and task significance, but not when food app workers engage in high levels of job crafting.

Food app workers can apply job crafting, and each crafting sub-form, in multiple ways. For instance, they can engage in approach-oriented task crafting by bringing an order to a customer's door instead of waiting on the pavement for someone to pick it up. As such, task variety will increase. Although this is only a small change, research shows that even small adjustments cause a significant difference [33]. Next, food app workers can apply relational crafting by having a quick chat with satisfied customers. The core tenet here is that even short-term connections with others can be highly consequential, especially with people who enable them to feel a sense of dignity, pride, or worth [14, 39]. Finally, an example of cognitive crafting is a food app worker who perceives the fulfillment of daily tasks as a process to positively impact the lives of customers, rather than a simple task assignment. As such, workers are better able to keep the ultimate fruits of their job for themselves or others in mind.

In short, while algorithmic control might be linked to low skill variety, task identity, and task significance, job crafting might compensate for this deficiency and thus acts as a moderator. Put differently, we expect the following hypothesis to be true:

Hypothesis 2: Daily job crafting moderates the negative relationship between, on the one hand, daily algorithmic control and, on the other hand, (a) daily skill variety, (b) daily task identity, and (c) daily task significance in that this relationship will be less strong when job crafting is high (compared to low)

\section{Methods}

\subsection{Participants and procedure}

This daily diary study was conducted among Belgian food app workers working with the Deliveroo, Uber Eats, and/or Takeaway apps on a regular basis (i.e., at least four hours a week). Participants were recruited in the public area with flyers (i.e., by addressing them on the street) and through social media such as Facebook and LinkedIn (i.e., by posting our flyers in rider communities and/or sending personal invites). In doing so, potential participants were told that the research would investigate their daily job characteristics and daily well-being. Respondents participated voluntarily and received a $€ 10$-gift voucher after completing the whole study consisting of five online surveys (i.e., a general questionnaire and four daily questionnaires). The general questionnaire measured the demographics (e.g., age, gender,..) and control variables (e.g., app working for, average working hours,...). Participants received 10 days to complete this survey (i.e., from Monday until Wednesday one week later). The following days (i.e., starting from Thursday), the daily diary questionnaires, which measured the focal variables of this study, were send out one after another (i.e., one questionnaire each day). Participants were asked to complete four daily diary studies. However, 
since some participants did not work every day, we sent out the diary questionnaires for eight days so that everyone could complete four daily diary questionnaires. We consciously chose to start on Thursday as this allowed us to include both work and weekend days. This is important since weekend days might be busier compared to weekdays and, as such, require more algorithmic control. Participants were asked to complete these surveys right after finishing their workday and received access to them via a link in email or WhatsApp.

In total, 84 participants completed the general survey, while 51 participants completed at least two daily surveys (i.e., dropout of 39\%). Together, the 51 participants filled in 196 diary questionnaires (i.e., 196 days within 51 individuals). Of the 51 respondents, 19 (37\%) used the Takeaway app, 15 (29\%) used the Deliveroo app, 9 (18\%) used the Uber Eats app, 7 (14\%) used both the Deliveroo and Uber Eats app, and 1 used both the Takeaway and Uber Eats app. Participants were on average 26 years old ( $\mathrm{SD}=6.46)$, had 21 months of experience as food app workers $(\mathrm{SD}=17.33)$, and worked on average 16 hours a week $(\mathrm{SD}=7.32)$. Moreover, $84 \%$ were men, while $16 \%$ were women.

\subsection{Measures}

Since not every food app worker was able to speak Dutch (i.e., one of the main languages in Belgium), questionnaires were provided in Dutch and English. In total, 37 participants completed the surveys in Dutch, while 14 participants completed them in English. We made the Dutch versions of the scales using a translation back-translation procedure. All variables were measured using a 7-point Likert scale ranging from 1 ("Totally disagree") to 7 ("Totally agree"). To make sure that the Dutch-speaking participants understood the questionnaires in the same way as the English-speaking participants, we conducted measurement invariance tests for all scales to examine whether the overall factor structure is equal to both groups. Because of space constraints that are inherent to diary studies [40], we used validated short versions of original scales to measure the daily variables. If not available, we compressed original scales based on the items with the highest factor loadings reported in previous research. The scales in the diary surveys were rewritten so that they captured daily (rather than general) behaviors (e.g. "Today, during work..."). An overview of all items can be found in Appendix 1.

4.2.1. Daily algorithmic control was measured with a self-developed scale based on the conceptualization of Möhlmann et al. [4]. The scale consisted of 4 items (e.g., "Today, I had the feeling of being under constant surveillance and control by the app"). An exploratory factor analysis using principal components showed that all items loaded well on a single factor (see Appendix 1 for factor loadings). In addition, Cronbach alpha's ranged from .85 to $.91(\mathrm{M}=.88)$. The measurement invariance test found no differences between the Dutchand English-speaking $\left(\Delta \chi^{2}=2.63 ; \mathrm{df}=3 ; \mathrm{p}=.45\right)$.

4.2.2. Daily skill variety, task identity, and task significance were measured using a shortened version of the scale developed by Idaszak and Drasgow [41]. The scale consisted of 6 items, with 2 items for each job characteristic. Rather than Cronbach alpha's, we used Spearman-Brown split-half to assess the inter-reliability (since Cronbach's Alpha is insufficient whit two items). Spearman-Brown split half ranged from: .88 to .90 (M $=.89$ ) for skill variety (e.g., "Today, my work required me to use a number of complex or high-level skills."), .67 to $.88(\mathrm{M}=.80)$ for task identity (e.g., "Today, I did a 'whole' and identifiable piece of work."), and .66 to $.83(\mathrm{M}=.74)$ for task significance (e.g., "Today, I could affect a lot of other people with my work.). Results of the measurement invariance test showed no differences between both groups $\left(\Delta \chi^{2}=8.18 ; \mathrm{df}=5 ; \mathrm{p}=.15\right)$.

4.2.3. Daily meaningful work was measured using the 3-item scale of Spreitzer [42] (e.g., "Today, my work was very important to me."; $\alpha=.73-.90 ; M=.85)$. Again, the measurement invariance test showed no differences between both groups $\left(\Delta \chi^{2}=.22 ; \mathrm{df}=2 ; \mathrm{p}=.89\right)$.

4.2.4. Daily job crafting was measured using 12 items of the scale developed by Bindl and colleagues [43], which were adjusted to the specific context of food app work. Although this scale includes both approach and avoidance items of task, relational, and cognitive crafting, we only included the approach-oriented items as this was in line with our theorizing on Hypothesis 2 . Cronbach alpha's were satisfying, i.e. $\alpha=.75-.83(\mathrm{M}=$ .79) for task crafting (e.g., "Today during work, I actively took on more tasks."), $\alpha=.84-.96(\mathrm{M}=.90)$ for relational crafting (e.g., "Today during work, actively tried to meet new people (e.g. other riders, customers,...)."), and $\alpha=.73-.87$ ( $\mathrm{M}=.79)$ for cognitive crafting (e.g., "Today during work, I thought about new ways of viewing my overall job."). Also here, the measurement invariance test found no differences between the Dutch and English speaking groups $\left(\Delta \chi^{2}=\right.$ $1.94 ; \mathrm{df}=3 ; \mathrm{p}=.58$ for task crafting, $\Delta \chi^{2}=7.01 ; \mathrm{df}=3$; $\mathrm{p}=.07$ for relational crafting, and $\Delta \chi^{2}=1.84 ; \mathrm{df}=3 ; \mathrm{p}$ $=.61$ for cognitive crafting). To test the moderating effect, we calculated a total mean score of job crafting, which is common in job crafting research [e.g., 44, 45].

\subsection{Controls}

We controlled for tenure (in that more experience might mean more meaningfulness) and the average number of working hours per week (in that more working hours might mean more meaningfulness) [46]. 
In addition, we controlled for job autonomy (measured with a scale developed based on the research of Möhlmann et al [4]; e.g., "In my job, I have the freedom to jump in and out of the app."; $\alpha=.70$ ) as this is a fundamental antecedent of job crafting [47]. Finally, we controlled for the apps food app workers worked for because differences between the food apps exist [21].

\subsection{Analyses}

Since the data was collected on multiple days, the data features a hierarchical structure with days nested within individuals. Consequently, multilevel (moderated mediation) within-person analyses were conducted in MLwiN [48] because single regression models would fail to recognize the clustering of the data [49]. To check whether multilevel analyses were justified, we first calculated the intraclass correlation coefficient (i.e., ICC) of all level 1 variables. Multilevel regressions should be conducted when level 1 variables exhibit more than $5 \%$ within-person variation (i.e., 1ICC). In a second step, the multilevel regression analyses were composed hierarchically, meaning that we built our model by adding variables step by step. We executed a Likelihood-Ratio test (LRT), based on the 2Log-likelihood values, to assess whether the inclusion of additional variables led to a significant improvement in model fit. However, due to space constraints, we only reported the final version of each model. All level 1 variables were person-mean centered, while all level 2 variables were grand-mean centered, which is common in organizational behavior research [40].

\section{Results}

In a first step, we examined the means, standard deviations, and intraclass correlation coefficients (see Table 1). As assumed, all level 1 variables significantly fluctuated daily. Moreover, it is remarkable that skill variety is lower than the other two job characteristics.

Table 1. Mean, SD, and 1-ICC

\begin{tabular}{lccc} 
& M & SD & 1-ICC \\
\hline Job autonomy & 4.57 & 1.24 & \\
Tenure (in months) & 21.66 & 17.78 & \\
Weekly working hours & 16.35 & 7.27 & \\
Deliveroo (1= yes; 0 = no) & 0.43 & 0.50 & \\
Takeaway (1= yes; 0=no) & 0.39 & 0.49 & \\
Uber Eats (1= yes; 0=no) & 0.33 & 0.47 & \\
Daily algorithmic control & 3.50 & 1.51 & $23 \%$ \\
Daily skill variety & 3.12 & 1.60 & $32 \%$ \\
Daily task identity & 4.84 & 1.38 & $35 \%$ \\
Daily task significance & 4.46 & 1.33 & $33 \%$ \\
Daily meaningful work & 4.39 & 1.35 & $35 \%$ \\
Daily job crafting & 3.60 & 1.16 & $31 \%$ \\
\hline
\end{tabular}

The results of the moderated-mediation analyses can be found in Table 2. In line with Hypothesis $1 a$, we found a significant negative relationship between daily algorithmic control and daily meaningful work $(\mathrm{B}=-$ $.29, \mathrm{p}<.001)$. This means that on days when food app workers perceive a lot of algorithmic control, they find their work less meaningful. However, in contrast to Hypothesis $1 b$, this relationship was not mediated by the three vital job characteristics. In particular, we found no significant relationships between, on the one hand, daily algorithmic control and, on the other hand, daily skill variety $(\mathrm{B}=.08, \mathrm{p}=.71)$, task identity $(\mathrm{B}=-.17, \mathrm{p}=.34)$, and task significance $(\mathrm{B}=.15, \mathrm{p}=.36)$. This implies that daily algorithmic control did not lead to a reduction in these job characteristics. Moreover, we only found a significant positive relationship between daily task significance and daily meaningful work $(\mathrm{B}=.14, \mathrm{p}<$ .01 ), but not between the other two core job characteristics and daily meaningful work $(\mathrm{B}=.03, \mathrm{p}=$ .33 for daily skill variety, and $\mathrm{B}=.03, \mathrm{p}=.38$ for daily task identity). Consequently, no mediation analyses were required.

Finally, Hypothesis 2 is partially supported. Indeed, daily job crafting moderated the relationship between daily algorithmic control and daily skill variety $(\mathrm{B}=.70$, $\mathrm{p}<.05)$. However, in contrast to our expectations, daily job crafting did not moderate the relationship between daily algorithmic control and daily task identify $(\mathrm{B}=$ $.17, \mathrm{p}=.59)$ nor daily task significance $(\mathrm{B}=-.30, \mathrm{p}=$ .31). To interpret the significant interaction effect, it is plotted in Figure 2. Here it can be seen that the relationship between daily algorithmic control and daily skill variety is negative for app workers scoring low on job crafting (i.e. one standard deviation below average), but positive for app workers scoring high on job crafting (i.e. one standard deviation above average). In line with our expectations, this implies that job crafting enables app workers experiencing higher algorithmic control (which is detrimental to meaningful work) to use more complex skills (i.e., skill variety).

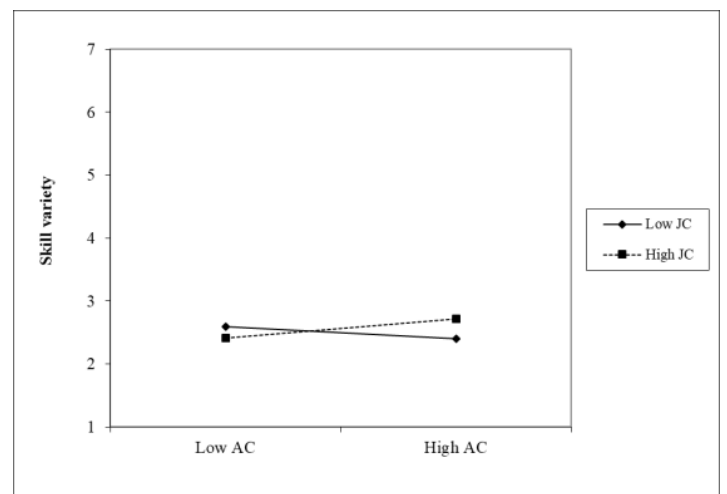

Figure 2. Moderation effect of daily job crafting 
Table 2. Multi-level moderated mediation regression analyses

\begin{tabular}{|c|c|c|c|c|c|c|c|c|}
\hline & \multicolumn{2}{|c|}{ Daily skill variety } & \multicolumn{2}{|c|}{$\begin{array}{c}\text { Daily task } \\
\text { identity }\end{array}$} & \multicolumn{2}{|c|}{$\begin{array}{c}\text { Daily task } \\
\text { significance }\end{array}$} & \multicolumn{2}{|c|}{$\begin{array}{c}\text { Daily } \\
\text { meaningful } \\
\text { work }\end{array}$} \\
\hline & $\mathrm{B}$ & SE & B & SE & B & SE & $\mathrm{B}$ & SE \\
\hline Intercept & $5.07^{* * *}$ & 1.39 & $9.42^{* * *}$ & 1.11 & $7.88^{* * *}$ & 1.19 & $4.24^{* * *}$ & .57 \\
\hline Job autonomy & .60 & .51 & .16 & .41 & 47 & .44 & .05 & .21 \\
\hline Tenure & -.05 & .02 & -.02 & .02 & -.02 & .02 & -.02 & .01 \\
\hline Average weekly working hours & -.01 & .05 & $-.09^{*}$ & .04 & .01 & .04 & .02 & .02 \\
\hline Deliveroo $(1=$ yes; $0=$ no $)$ & .28 & 1.35 & 1.57 & 1.08 & -.09 & 1.16 & .18 & .56 \\
\hline Takeaway $(1=$ yes; $0=$ no $)$ & 1.28 & 1.61 & 0.11 & 1.29 & 1.70 & 1.39 & -.32 & .67 \\
\hline Uber Eats $(1=$ yes; $0=$ no $)$ & 1.63 & 1.09 & -1.21 & .87 & 1.10 & .94 & .52 & .45 \\
\hline Daily algorithmic control (AC) & .08 & .20 & -.17 & .18 & .15 & .17 & $-.29^{* * * *}$ & .08 \\
\hline Daily job crafting (JC) & .13 & .23 & $.43^{*}$ & .20 & $.58^{* *}$ & .19 & $.29^{* *}$ & .09 \\
\hline Interaction $(\mathrm{AC} \times \mathrm{JC})$ & $.70^{*}$ & .35 & .17 & .31 & -.30 & .29 & & \\
\hline Daily skill variety & & & & & & & .03 & .03 \\
\hline Daily task identity & & & & & & & .03 & .04 \\
\hline Daily task significance & & & & & & & $.14^{* *}$ & .04 \\
\hline -2 Log-likelihood & 899.85 & & 841.63 & & 826.63 & & 529.78 & \\
\hline
\end{tabular}

Note: $\mathrm{N}=196$ days nested within 51 indivuals. All daily (Level 1) variables are person-mean centered, while general (Level 2) variables are grand-mean centered. ${ }^{*} p<.05 .{ }^{* \star} p<.01 .{ }^{\star \star *} p<.001$

\section{Discussion}

At the beginning of this article, we posed two research questions that we aim to answer with our research: How is daily algorithmic control related to app workers' work meaningfulness, and how can app workers cope with the psychological costs related to algorithmic control? In what follows, we discuss the most important findings and contributions when answering these questions.

A first important contribution of this study is that it shows a significant drawback of algorithmic control for individual app workers. This is in line with previous research [e.g., 10, 14, 16]. As expected with Hypothesis 1a, we found a negative relationship between daily algorithmic control and work meaningfulness. This implies that app workers might be faced with a lack of meaningful work experiences due to algorithmic control. On average only $31 \%$ of the respondents experienced their work to be meaningful on a daily basis (i.e., $M \geq 5$ ). Making use of more algorithmic control (i.e. top-down) might even worsen this. Since a lack of work meaningfulness is deteriorating for workers' well-being and performance outcomes [11], it is of interest to both app providers and app workers to eliminate the over-controlling characteristic of algorithmic control. Indeed, although app providers might benefit from algorithmic control from an economic perspective (e.g., increased efficiency) [50], it is disadvantageous from a psychoorganizational perspective (e.g., reduced performance).

It should be noted that the relationship between daily algorithmic control and daily work meaningfulness was not mediated by the three vital job characteristics as proposed by JCT (i.e., Hypothesis 1b). We propose two possible explanations for that. On the one hand, it might be that the relationship between algorithmic control and work meaningfulness is explained by other mediating mechanisms. Because technology - such as algorithms - creates new job characteristics, it might be that app workers perceive meaningful work experiences through these new job characteristics. For instance, app workers might perceive their job as meaningful when they receive good ratings from satisfied customers. On the other hand, because JCT is founded at a between-person level, it cannot simply be mirrored to a within-person level. Although a substantial amount of the total variation in job characteristics and meaningful work was attributable to the within-person level, we only found one vital job characteristic (i.e., task significance) to be positively related to meaningfulness at a within-person level. Post-hoc analyses, however, showed that significant relationships between the three vital job characteristics and meaningful work did occur at the between-person level. This finding is in line with other work design frameworks and theories. For instance, some assumptions of the job demands-resources model are 
found to be different whether they are viewed at within- or between-person level [51].

Another important contribution is that we introduced job crafting as a fruitful coping mechanism for app workers. In line with Hypothesis 2, job crafting enabled app workers to experience higher skill variety on days of high algorithmic control. Moreover, daily job crafting enabled app workers to experience high task identity, task significance, and meaningful work independent of the experience algorithmic control. All of this implies that food app workers themselves have considerable latitude to (re)design their job. Thus, although it was originally assumed that jobs can only be (re)created in a top-down direction (i.e., managers have the primary responsibility for (re)designing jobs) with algorithmic control being a detrimental factor [52], individual food app workers can reshape their job in a bottom-up direction.

\section{Conclusion}

This study found evidence for the detrimental role of daily algorithmic control on food app workers' work meaningfulness. Although we did not find support for the mediation effect based on JCT, we found a direct negative relationship between daily algorithmic control and work meaningfulness. In addition, we unraveled that daily job crafting is an effective strategy for food app workers to attain skill variety in case of high algorithmic control and to increase task identity, task significance, and meaningful work.

These findings provide some highly relevant insights for both (food) app workers and app providers. In particular, because meaningful work is related to a broad spectrum of individual and organizational outcomes (e.g., work engagement and turnover intentions) [7], creating meaningful jobs within the context of app work is important [53]. As such, we echo the call of scholars [e.g., 54] to step away from 'digital Taylorism' by designing algorithms that energize rather than deplete app workers.

Food app providers can do so by reducing the degree of algorithmic control and encouraging job crafting. However, as highlighted by previous scholars [e.g., 55], - following a market logic - app providers might not have any incentives to actually redesign jobs. Since there are enough workers to replace food app workers who leave the platforms, food app providers are not significantly affected by the disadvantages associated with jobs that lack meaning. Therefore, we encourage food app workers to engage in job crafting as this might be a particularly fruitful strategy to create meaningful experiences in their daily work activities. Our research has clearly indicated that daily job crafting might be important for the satisfaction of daily meaningful work and motivating job characteristics. These implications might be relevant to other gig workers too. For instance, just like app providers, crowd work providers (e.g., Amazon Mechanical Turk) often lack incentives to create meaningful work experiences. As such, crowd workers might engage in job crafting too.

Besides its merits, this research comes with some limitations. First, our results are based on a relatively small sample size (i.e., 51 respondents), which may have biased our results but is a common problem in diary research [e.g., 56]. Therefore, replicating the study with a larger sample size might lead to more indepth and even more convincing results. Second, our sample might not fully represent the diverse population of Belgian food app workers. Although we offered questionnaires in both Dutch and English to reduce language barriers, a considerable amount of food app workers might not have mastered either language and, therefore, could not participate in the study. As such, future research might offer questionnaires in additional languages (e.g., French). Moreover, we only recruited app workers who conducted the job on a regular basis. Because only $14 \%$ of our sample worked less than 10 hours per week, our results might apply to a lesser extent to app workers who do this work only sporadically (e.g., working students). Fourth, we conducted our study during the COVID-19 crisis. Although our data was collected in a period with relatively mild COVID-19 measures, this might have biased our results. For instance, our participants may have experienced fewer opportunities to engage in relational crafting because people tried to limit their social interactions. Finally, the incentivized sample might have biased our results because participants who are paid for survey time might answer questions differently from participants who are not paid [57]. However, we included multiple control mechanisms such as reverse coding to testing the reliability of participant's answers. In addition, a recent meta-analysis has shown that incentivized samples show similar reliabilities and criterion validities of non-incentivized samples [58].

\section{References}

[1] J. Duggan, U. Sherman, R. Carbery, and A. McDonnell, "Algorithmic management and app-work in the gig economy: A research agenda for employment relations and HRM", Human Resource Management Journal, vol. 30, no. 1, pp. 114-132, 2020.

[2] K. Griesbach, A. Reich, L. Elliott-Negri, and R. Milkman, "Algorithmic control in platform food delivery”, Socius, vol. 5, pp. 1-15, 2019. 
[3] M. K. Lee, D. Kusbit, E. Metsky and L. Dabbish, "Working with Machines: The Impact of Algorithmic, Data-Driven Management on Human Workers," in 33rd Annual ACM SIGCHI Conference, 2015.

[4] M. Möhlmann, L. Zalmanson, O. Henfridsson, and R.W. Gregory, "Algorithmic management of work on online labor platforms: when matching meets control", $M I S$ Quarterly: Management Information Systems, pp. 1-54, 2020.

[5] N. Glozier, "Review of evidence of psychosocial risks for mental ill-health in the workplace," Gov.au. [Online]. Available:https://www.safework.nsw.gov.au/_data/asse ts/pdf_file/0007/360448/SW09005-0518-418530-

Review-of-Evidence-of-Psychosocial-Risks-for-Mental....pdf.

[6] K.C. Kellogg, M.A. Valentine, and A. Christin, "Algorithms at work: The new contested terrain of control", Academy of Management Annals, vol. 14, no. 1, pp. 366-410, 2020.

[7] B.A. Allan, C. Batz-Barbarich, H.M Sterling, and L. Tay, "Outcomes of meaningful work: A metaanalysis", Journal of management studies, vol. 56, no. 3, pp. 500-528, 2019.

[8]A. Ropponen, J.J Hakanen, M. Hasu, and L. Seppänen, "Workers' Health, Wellbeing, and Safety in the Digitalizing Platform Economy", in Digital Work and the Platform Economy: Understanding Tasks, Skills and Capabilities in the New Era, Routledge, New York, 2019.

[9] D. McGregor, and J. Cutcher-Gershenfeld, The human side of enterprise, McGraw-Hill, New York, vol 21, pp. $166,1960$.

[10] A.J. Wood, M. Graham, V. Lehdonvirta, and I. Hjorth, "Good gig, bad gig: Autonomy and algorithmic control in the global gig economy", Work, Employment and Society, vol. 33, no.1, pp. 56-75, 2019.

[11] J. Woodcock, and M.R. Johnson, "Gamification: What it is, and how to fight it", The Sociological Review, vol. 66, pp. 542-558, 2018

[12] G. Petriglieri, S. J. Ashford, and A. Wrzesniewski, "Agony and ecstasy in the gig economy: Cultivating holding environments for precarious and personalized work identities," Administrative Science Quarterly, vol. 64, no. 1, pp. 124-170, 2019.

[13] S. J. Ashford, B. B. Caza, and E. M. Reid, "From surviving to thriving in the gig economy: A research agenda for individuals in the new world of work," Research in Organizational Behavior, vol. 38, pp. 23-41, 2018.

[14] L. Verelst, L. Lemmens, R. De Cooman, and M. Verbruggen, "From flailing to gaining app workers: shedding light on the job characteristics in app work and how app workers can craft them" In European Academy of Occupational Health Psychology Conference, 2020.

[15] X.N. Deng, and K.D. Joshi, "Why individuals participate in micro-task crowdsourcing work environment: Revealing crowdworkers' perceptions", Journal of the Association for Information Systems, vol. 17, no. 10, pp. 711-736, 2016.

[16] X. Parent-Rocheleau, and S.K. Parker, "Algorithms as work designers: How algorithmic management influences the design of jobs", Human Resource Management Review, in press.

[17] S.K. Parker, and G. Grote, G, "Automation, algorithms, and beyond: Why work design matters more than ever in a digital world", Applied Psychology, 2020.

[18] J.R., Hackman, and G.R. Oldham, "Motivation through the design of work: Test of a theory", Organizational behavior and human performance, vol. 16, no. 2, pp. 250279, 1976.

[19] A. Shapiro, "Between autonomy and control: Strategies of arbitrage in the "on-demand" economy," New Media \& Society, vol. 20, pp. 2954-2971, 2018.

[20] G.M. Spreitzer, L. Cameron, and L. Garrett, “ Alternative work arrangements: Two images of the new world of work", Annual Review of Organizational Psychology and Organizational Behavior, vol. 4, pp. 473499, 2017.

[21] D. Farrell, F. Greig, and A. Hamoudi, "The online platform economy in 2018: Drivers, workers, sellers, and lessors." JPMorgan Chase Institute, 2018.

[22] A. Veen, T. Barratt, and C. Goods, “ Platform-capital's 'app-etite'for control: A labour process analysis of fooddelivery work in Australia", Work, Employment and Society, vol. 34, no. 3, pp. 388-406, 2020.

[23] S. Schafheitle, A. Weibel, I. Ebert, G. Kasper, C. Schank, and U. Leicht-Deobald, "No stone left unturned? Toward a framework for the impact of datafication technologies on organizational control", Academy of Management Discoveries, vol. 6(3), pp. 455-487, 2020

[24] A. Rosenblat and L. Stark, "Algorithmic Labor and Information Asymmetries: A Case Study of Uber's Drivers", International Journal of Communication, vol. 10, pp. 3758-3784, 2016.

[25] L. Evans, and R. Kitchin, "A smart place to work? Big data systems, labour, control and modern retail stores" New Technology, Work and Employment, vol. 33, no. 1, pp. 44-57, 2018.

[26] D. R. May, R. L. Gilson, and L. M. Harter, "The psychological conditions of meaningfulness, safety and availability and the engagement of the human spirit at work," Journal of Occupational and Organizational Psychology, vol. 77, no. 1, pp. 11-37, 2004.

[27] F. Tommasi, A. Ceschi, and R. Sartori, "Viewing Meaningful Work Through the Lens of Time", Frontiers in psychology, vol. 11, 3121, 2020.

[28] J.S. Bunderson, and J.A. Thompson, "The call of the wild: Zookeepers, callings, and the double-edged sword of deeply meaningful work", Administrative Science Quarterly, vol. 54, no.1, pp. 32-57, 2009.

[29] C. Bailey, R. Yeoman, A. Madden, M. Thompson, and G. Kerridge, "A review of the empirical literature on meaningful work: Progress and research agenda", Human Resource Development Review, vol. 18, no. 1, pp. 83-113, 2019.

[30] D. Duchon, and D.A. Plowman, "Nurturing the spirit at work: Impact on work unit performance" The Leadership Quarterly, vol. 16, pp. 807-833, 2015.

[31] S.E. Humphrey, J.D. Nahrgang, and F.P. Morgeson, "Integrating motivational, social, and contextual work design features: a meta-analytic summary and theoretical 
extension of the work design literature", Journal of Applied Psychology, vol. 92, no. 5, pp. 1332-1356, 2007.

[32] A. Wrzesniewski, and J.E Dutton, "Crafting a job: Revisioning employees as active crafters of their work", Academy of Management Review, vol. 26, no.2, pp. 179-201, 2001

[33] J.M. Berg, J.E. Dutton, and A. Wrzesniewski, "Job crafting and meaningful work". In Purpose and meaning in the workplace, American Psychological Association, Washington, 2013.

[34] M. Tims, and A.B. Bakker. "Towards a new model of individual job redesign", South African Journal of Industrial Psychology, vol. 36, pp.1-9, 2010.

[35] P. F. Bruning and M. A. Campion, "A role-resource approach-avoidance model of job crafting: A multimethod integration and extension of job crafting theory," Academy of Management Journal, vol. 61, no. 2, pp. 499-522, 2018.

[36] Q. Hu, T. W. Taris, M. F. Dollard, and W. B. Schaufeli, "An exploration of the component validity of job crafting," European Journal of Work and Organizational. Psychology, vol. 29, no. 5, pp. 776-793, 2020.

[37] K. Levy, and S. Barocas, "Refractive surveillance: Monitoring customers to manage workers", International Journal of Communication, vol. 12, pp. 1166-1188, 2018.

[38] M.E. Debus, C. Gross, and M. Kleinmann, "The power of doing: How job crafting transmits the beneficial impact of autonomy among overqualified employees", Journal of Business and Psychology, vol. 35, no.3, pp. 317-331, 2020.

[39] J.E. Dutton, and E.D. Heaphy, "The power of highquality connections", Positive organizational scholarship: Foundations of a new discipline, vol. 3, pp. 263-278, 2003.

[40] Ohly, S., Sonnentag, S., Niessen, C., \& Zapf, D. (2010). Diary studies in organizational research. Journal of Personnel Psychology.

[41] J.R. Idaszak, and F. Drasgow, "A revision of the Job Diagnostic Survey: Elimination of a measurement artifact", Journal of applied psychology, vol. 72, no. 1, pp. 69-74, 1987.

[42] G.M Spreitzer, "Psychological empowerment in the workplace: Dimensions, measurement, and validation", Academy of Management Journal, vol. 38, no. 5, pp. 1442-1465, 1995.

[43] U.K. Bindl, K.L. Unsworth, C.B. Gibson, and C.B. Stride, "Job crafting revisited: Implications of an extended framework for active changes at work", Journal of Applied Psychology, vol. 104, no. 5, pp. 605-628, 2019.

[44] J. J. Hakanen, P. Seppälä, and M. C. W. Peeters, "High job demands, still engaged and not burned out? The role of job crafting," International Journal of Behavioral Medicine, vol. 24, no. 4, pp. 619-627, 2017.

[45] R. M. Vogel, J. B. Rodell, and J. W. Lynch, "Engaged and productive misfits: How job crafting and leisure activity mitigate the negative effects of value incongruence," Academy of Management Journal, vol. 59, no. 5, pp. 1561-1584, 2016.

[46] M.H. Doucette, and W.D. Bradford, "Dual job holding and the gig economy: Allocation of effort across primary and gig jobs", Southern Economic Journal, vol. 85, no. 4, pp. 1217-1242, 2019.

[47] C.W. Rudolph, I.M. Katz, K.N. Lavigne, and H. Zacher; "Job crafting: A meta-analysis of relationships with individual differences, job characteristics, and work outcomes", Journal of Vocational Behavior, vol. 102, pp. 112-138, 2017.

[48] J. Rashbash, W. Browne, M. Healy, B. Cameron, and C. Charlton, "MLwiN (Version 1.10. 006): Interactive software for multilevel analysis", London, UK: Multilevel Models Project, Institute of Education, University of London, 2000.

[49] P. Clarke, "When can group level clustering be ignored? Multilevel models versus single-level models with sparse data" Journal of Epidemiology \& Community Health, vol. 62, pp. 752-758, 2008.

[50] M. Liu, E. Brynjolfsson, and J. Dowlatabadi, "Do digital platforms reduce moral hazard? The case of Uber and taxis," Management Science, vol. 67, no. 8, pp. 46654685, 2021.

[51] E. Demerouti, and A.B. Bakker, "The Job DemandsResources model: Challenges for future research", $S A$ Journal of Industrial Psychology, vol. 37, no. 2, pp. 1-9, 2011.

[52] G.R. Oldham, and J.R. Hackman, "Not what it was and not what it will be: The future of job design research", Journal of organizational behavior, vol. 31, no. 2, pp. 463-479, 2010.

[53] N. Jabagi, A.-M. Croteau, L. K. Audebrand and J. Marsan, "Gig-workers' motivation: thinking beyond carrots and sticks," Journal of Managerial Psychology, vol. 34, no. 4, pp. 192-213, 2019.

[54] E. Demerouti, "Turn digitalization and automation to a job resource," Applied Psychology, pp. 1-6, 2020.

[55] T., Christaens, "Digital Biopolitics And The Problem Of Fatigue In Platform Capitalism in Big Data $-A$ New Medium?, Routledge, New York, 2020.

[56] M. Tims, A.B. Bakker, and D. Derks, D. " Daily job crafting and the self-efficacy-performance relationship", Journal of Managerial Psychology, vol. 29, no. 5, pp. 490-507, 2014

[57] M. Kim, and T.A. Beehr, "The role of organizationbased self-esteem and job resources in promoting employees' job crafting behaviors", The International Journal of Human Resource Management, pp. 1-28, 2021.

[58] S.L. Walter, S.E. Seibert, D. Goering, and E.H. O'Boyle, "A tale of two sample sources: Do results from online panel data and conventional data converge?", Journal of Business and Psychology, vol. 34, no. 4, pp. 425-452, 2019. 


\section{Appendix 1}

\begin{tabular}{|c|}
\hline Daily algorithmic control [4] \\
\hline Today... \\
\hline $\begin{array}{l}\text { AC1: ...I had the feeling of being under constant surveillance and control by } \\
\text { the app. }(\mathrm{FL}=.84)\end{array}$ \\
\hline $\begin{array}{l}\mathrm{AC} 2: . . . \mathrm{I} \text { had the feeling that there is close supervision because of the app's } \\
\text { instructions. ( } \mathrm{FL}=.83 \text { ) }\end{array}$ \\
\hline $\begin{array}{l}\text { AC3: ...I felt under pressure to accept the rides/hours/... that are suggested } \\
\text { by the app. }(\mathrm{FL}=.83)\end{array}$ \\
\hline $\begin{array}{l}\text { AC4: ...I felt forced to follow instructions because I was afraid to be } \\
\text { blocked from the app. }(\mathrm{FL}=.90)\end{array}$ \\
\hline Daily skill variety [36] \\
\hline Today... \\
\hline SK1:...my work required me to use a number of complex or high-level skills. \\
\hline $\begin{array}{l}\text { SK2...my work allowed me to use a number of complex or high-level } \\
\text { skills. }\end{array}$ \\
\hline Daily task identity [36] \\
\hline Today... \\
\hline $\begin{array}{l}\text { TI1: ...my work was arranged so that I could do an entire piece of work from } \\
\text { beginning to end }\end{array}$ \\
\hline TI2:......I did a 'whole' and identifiable piece of work. \\
\hline Daily task significance [36] \\
\hline Today... \\
\hline TS1:...I could affect a lot of other people with my work. \\
\hline $\begin{array}{l}\text { TS2:...my work was very significant and important in the broader } \\
\text { scheme of things. }\end{array}$ \\
\hline Daily meaningful work [37] \\
\hline Today.... \\
\hline MW1:...my work was very important to me. \\
\hline MW2:...my job activities were personally meaningful to me. \\
\hline MW3:...the work I did was meaningful to me. \\
\hline Daily job crafting [38] \\
\hline Today during work, I... \\
\hline JC1:... actively took on more tasks. \\
\hline JC2:... added complexity to my tasks by changing their structure or order. \\
\hline JC3:...changed my tasks so that they were more challenging. \\
\hline JC4:...increased the number of difficult decisions I made in my work. \\
\hline JC5:... actively tried to meet new people (e.g. other riders, customers,...). \\
\hline $\begin{array}{l}\text { JC6:...made efforts to get to know other people (e.g. other riders, } \\
\text { customers,...) better. }\end{array}$ \\
\hline $\begin{array}{l}\mathrm{JC} 7: \ldots \text { tried to interact with other people (e.g. other riders, customers,...) } \\
\text { regardless of how well I knew them. }\end{array}$ \\
\hline JC8:...tried to spend more time with a wide variety of people at work. \\
\hline JC9:...thought about how my job contributed to the organization's goals. \\
\hline $\begin{array}{l}\text { JC10:...thought about ways in which my job as a whole contributed to } \\
\text { society. }\end{array}$ \\
\hline $\begin{array}{l}\text { JC11:... focused my mind on the best parts of my job, while trying to ignore } \\
\text { those parts I didn't like. }\end{array}$ \\
\hline JC12:...thought about new ways of viewing my overall job. \\
\hline General job autonomy [4] \\
\hline In my job... \\
\hline JA1:...I have the flexibility to decide how much I work. \\
\hline JA2:...I have the flexibility to decide when I work. \\
\hline JA3:...I have the freedom to stop working. \\
\hline
\end{tabular}

